\title{
Repensando o lugar da representação, da transmissão e da experiência no ensino da Filosofia
}

Amanda Veloso Garcia

Graduanda em Filosofia pela UNESP - Campus de Marília

Rodrigo Pelloso Gelamo

Professor do Departamento de Didática da UNESP - Campus de Marília

\section{RESUMO}

A questão que procuramos desenvolver neste artigo pode ser enunciada do seguinte modo: será que o conhecimento pode ser transmitido de forma representacional, por meio de uma explicação, sem que aquele que aprende faça uma experiência por si só daquilo que aprende? Amparado-se no pensamento de Hume, Deleuze, Rancière e Gallo, pretende-se mostrar que somente a experiência com o objeto pode promover a aprendizagem efetiva, violentando o pensamento para que este busque por si só seu sentido e forme sua própria apreensão, e não a mera repetição de conteúdos partilhados e tidos como importantes, como temos encontrado nas escolas.

Palavras-chave: Ensino da Filosofia; Representação; Experiência.

\begin{abstract}
The question that we develop in this study can be proposed as follows: can knowledge be transmitted in a representational way through an explanation in such a way that the one who is learning does not have an experience itself of what he is learning? Grounded on Hume, Deleuze, Rancière and Gallo, we aim to show that only the experience with the object can promote effective learning, for violating the thought to search by itself for its meaning and for its own understanding, and not for the mere repetition of contents that have been shared and taken as important, as we have seen in schools.
\end{abstract}

Keywords: Teaching of Philosophy; Representation; Experience.

${ }^{1}$ Essa pesquisa contou com financiamento da CAPES e da FAPESP em sua realização.

Filosofia e Educação - ISSN 1984-9605 - v. 4, no 1, abril-setembro de 2012 
Ensino da Filosofia e suas relações: o nascimento de um problema

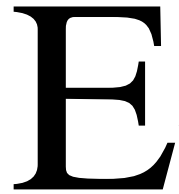

ste artigo é resultado de uma reflexão decorrente de nossa participação no projeto "Os limites e as possibilidades do ensino de Filosofia: análise do material São Paulo faz Escola". Tal projeto insere-se no Programa Institucional de Bolsa de Iniciação à Docência ${ }^{2}$ (PIBID), financiado pela CAPES, desenvolvido no Grupo de Estudos e Pesquisa sobre o Ensino da Filosofia, que está vinculado ao Grupo de Estudos e Pesquisa em Educação e Filosofia (GEPEF). O objetivo é compreender a prática do ensino da Filosofia nas escolas públicas do Estado de São Paulo. Para isso, escolheu-se como objeto de análise o material didático do Programa São Paulo Faz Escola, o qual, desde 2008, é utilizado pela rede pública do Estado e oferecido pela Secretaria da Educação. Acompanhamos sua aplicação em sala de aula durante dois anos, 2010 e 2011, e o analisamos nos encontros semanais com o grupo de pesquisa, preparando as aulas a serem ministradas durante a semana e avaliando as aulas ministradas na semana anterior. Esse procedimento foi realizado conjuntamente com o professor da escola responsável pela disciplina onde desenvolvemos o projeto. Vale ressaltar que o projeto foi desenvolvido em duas escolas diferentes, para que pudéssemos comparar os resultados. Nosso propósito, então, não era apenas a análise do material didático disponível para o professor, mas sua aplicabilidade nas situações de sala de aula para verificar seus limites e possibilidades em uma situação ensino-aprendizagem.

\footnotetext{
${ }^{2}$ O Programa Institucional de Bolsa de Incentivo à Docência (PIBID) é um programa financiado pela CAPES que tem por objetivo, como o próprio nome sugere, incentivar os cursos de licenciatura ao desenvolvimento de atividades docentes pelos alunos, vinculando essas atividades à pesquisa sobre as relações de ensino. O projeto do qual participamos está voltado para o ensino da Filosofia e da Sociologia no contexto do Estado de São Paulo. O grupo de alunos da Licenciatura da Filosofia procurou compreender os limites e possibilidades do ensino da Filosofia no Estado por meio da análise do material utilizado no Ensino Médio público paulista e do acompanhamento de aulas de Filosofia em duas escolas da cidade de Marília (SP) para verificar sua aplicabilidade em uma situação real.
}

Filosofia e Educação - ISSN 1984-9605 - v. 4, no 1, abril-setembro de 2012 
As relações estabelecidas no âmbito escolar através da tentativa de aplicar tal material nas escolas nos chamou a atenção para algo que talvez estivesse além da aplicabilidade do material didático de Filosofia. Atentamos para algo que estava implícito ou pressuposto nas relações pedagógicas que ocorriam em sala de aula: a transmissão de conhecimentos por parte do professor; melhor dizendo, os limites do ensino de Filosofia pautado em uma transmissão de conhecimento. Notamos tal pressuposto implícito no material que analisamos, uma vez que este pretende ensinar a Filosofia por meio da transmissão de conteúdos, partindo de tematizações que muitas vezes desconsideram a realidade de cada contexto escolar. Isto ficou evidente devido a nossa oportunidade de trabalhar em duas escolas diferentes, que embora fossem da mesma cidade - Marília (SP) apresentaram contextos, apesar de ser o mesmo professor o responsável pela disciplina em ambas, e consequentemente resultados, completamente diversos.

Em nossa análise, a desconsideração do contexto na enunciação temática do material didático se mostrou a faceta mais preocupante do ensino da Filosofia, pois tal área do saber se preocupa principalmente com as formas de pensar, uma vez que, em geral, as definições de "Filosofia" sempre estão ligadas de alguma forma a um processo de pensamento. Nesta perspectiva, transmitir informações prontas aos alunos, desconsiderando o contexto em que estão inseridos, não parece promover a aprendizagem filosófica da Filosofia, mas sim fornecer conhecimentos abstratos sobre sua História. Dessa forma, o material oferecido e os procedimentos nele implícitos mostraram-se, além de ineficientes, desconsideram o interesse do aluno e não condiziam com a aprendizagem de fato filosófica da disciplina.

O contato com o ensino da Filosofia e principalmente as discussões suscitadas nas reuniões do grupo de pesquisa nos despertaram para uma problematização da relação entre a aprendizagem filosófica e a mera

Filosofia e Educação - ISSN 1984-9605 - v. 4, no 1, abril-setembro de 2012 
obtenção de conteúdos de Filosofia. Ao que nos parece, o acesso aos conteúdos da Filosofia promove nos alunos apenas o acúmulo de informações acerca da História da Filosofia não possibilitando a estes o filosofar, que é o cerne desta área do saber. Uma das questões que nos colocamos nesse contexto é, como fazer dos conhecimentos filosóficos, que são transmitidos, um filosofar na situação do ensino da filosofia?

Escolhemos alguns autores para nos acompanhar na problematização que pretendíamos fazer do material didático e das situações de ensino. Um deles foi Jacques Rancière. $\mathrm{O}$ contato com a obra $O$ Mestre Ignorante (2002) levou-nos a entender melhor aquilo que nos incomodava na relação entre o professor, o aluno e a Filosofia. Ajudou-nos a entender com mais precisão como esta relação que se dá em âmbito escolar passa a se constituir em um mito pedagógico, no qual o professor é concebido como alguém que tem de ter necessariamente um conhecimento maior que o do aluno e como detentor dos conhecimentos superiores a serem transmitidos.

Isto se tornou evidente em nossa análise feita durante o projeto PIBID. Conforme enunciamos anteriormente, esse projeto visava a analisar as situações escolares e a aplicação do material pedagógico utilizado nas escolas públicas do estado de São Paulo, o Programa São Paulo Faz Escola. Durante a análise desse material, notamos que o Caderno do Professor e Caderno do Aluno eram diferentes, não em conteúdos, mas na sua explicitação. No primeiro, o Caderno do Professor, o desenvolvimento dos conteúdos é maior, apresenta mais textos, mais explicações e inclusive diversas indicações de leitura, enquanto que no segundo, o Caderno do Aluno, apareciam poucos textos e não havia nenhuma sugestão de leitura. Podemos dizer que o material oferece uma "reserva de conhecimento" para o professor, garantindo que ele tenha mais informações diante de seus alunos. Essa relação, subtende que o estudante por si só não tem condições de realizar as mesmas leituras que seu professor e precisa que ele apresente

Filosofia e Educação - ISSN 1984-9605 - v. 4, no 1, abril-setembro de 2012 
ao aluno um pensamento já pronto, ou mais "simplificado", sobre determinado assunto ou pensamento filosófico, imaginando que o próprio aluno não seja capaz de fazê-lo.

A nosso ver, no material analisado, a relação professor-aluno está fundamentada em um modo de entender o ensino como sendo uma tarefa na qual o professor deve transmitir imagens representacionais, que são comumente denominados de "conhecimentos" ou "conteúdos", aos alunos. Ou seja, nessa relação subentende-se que a transmissão de conhecimentos se dá de tal forma que o professor, ao enunciar uma imagem representacional que criou de certo pensamento de um filósofo, pode comunicar ao seu aluno essa mesma imagem criada por ele, de modo que o aluno a receba e a assimile.

Tal tipo de relação parece-nos, no entanto, problemática, uma vez que esse processo de ensino está ancorado na transmissão abstrata e representacional de conhecimentos, desconsiderando a experiência que o professor e o aluno podem ter com o objeto, tanto no momento de enunciálo, como no processo de aprendizagem, em nosso caso, a Filosofia, o filosofar, os textos filosóficos e sua História.

Com isto, pode-se conceber a transmissão como uma comunicação, como um processo direto no qual um emissor transmite uma mensagem a um receptor e este a processa de tal modo a assimilá-la. No entanto, aqui, pressupõe-se que emissor e receptor compartilhem, ou precisem compartilhar, as mesmas representações que estão sendo transmitidas; caso contrário, o processo se torna inviável, pois a compreensão do outro poderá estar inadequada ou estar "errada" diante do que se pretendeu comunicar.

Pelo que pudemos notar em nossas observações em sala de aula, tal pressuposto comunicacional fundamenta a relação professor-aluno. É por meio da comunicação que o professor explica os conteúdos a fim de transmitir seus conhecimentos aos estudantes. Isto só é permitido por haver

Filosofia e Educação - ISSN 1984-9605 - v. 4, no 1, abril-setembro de 2012 
esta crença comum de que compartilhamos representações e que é possível transmiti-las por meio do discurso.

É esta relação comunicativo-representacional muitas vezes fundamenta o processo de ensino-aprendizagem tal qual comumente é concebido, tomado até mesmo pelo modo como é escrito - separado por um traço - como um processo direto. O indivíduo detentor do conhecimento, de uma representação de determinado objeto, transmite-o por meio da explicação a alguém que não o tem, proporcionando que este passe a possuílo, ou seja, que ele tenha a mesma representação acerca do mesmo objeto, sem que para isso ele tenha de ter tido um contato com o objeto em questão.

Esta faceta comunicacional do ensino promove um distanciamento do objeto, tanto por parte do professor, quanto por parte do aluno, o que parece não ser produtivo quando se trata de oferecer condições para que o aprendiz apreenda e pense sobre determinada coisa. Isso parece ser uma das causas para que o aluno apenas acumule algumas informações esparsas e abstratas sobre a Filosofia e não que tenha o seu pensamento afetado por esses conteúdos que o possam levar a filosofar ou que o deem a pensar na sua relação com aquilo que lhe é ensinado e com o mundo que o rodeia.

Outra possibilidade de pensar essa relação com o conhecimento é apresentada por David Hume em sua obra Investigação sobre o Entendimento Humano (1999, p. 24). Ele distingue as percepções da mente em duas espécies que se diferenciam justamente por seus graus de força e vivacidade. As consideradas menos fortes e menos vivas são as que geralmente denominamos ideias ou pensamento; já as mais vívidas são chamadas pelo autor de impressões. A fragilidade das ideias se deve ao fato de que estas não são o que perdura em nossa memória, pois por se tratarem do que não é vivido atualmente, são impressões fracas. Desse modo, elas tendem a serem esquecidas, tanto pela falibilidade da memória, quanto pela fragilidade de suas impressões. Por outro lado, para o autor, é através das

Filosofia e Educação - ISSN 1984-9605 - v. 4, no 1, abril-setembro de 2012 
impressões que podemos dizer que a nossa mente tem "habitantes" que se associam, ou seja, que nossa mente de fato funciona. Porém, aquilo que permanece em nosso pensamento são as impressões fortes. Diante disso, notamos que o que move o pensamento não são as percepções fracas - o que o autor chama de ideias e o que nós estamos chamando de representação -, estas não se sustentam se não estiverem o tempo todo sendo reafirmadas pela realidade. Neste sentido, o que nos dá a pensar é o mundo, isto é, como acredita Hume, as impressões vívidas e vividas que movem nosso pensamento, e não as representações que se tem dele.

O ensino baseado na apresentação de representações parece se dar no âmbito das ideias, se o pensarmos com Hume, pois aquilo que se oferece ao estudante é um contato com uma representação, as impressões fracas acerca de algo (aquilo que o professor ou a apostila diz sobre a Filosofia e sua História) e não com o objeto (o próprio texto filosófico, o pensamento do filósofo e com aquilo que o texto oferece ao aluno para que ele possa pensar e sustentar seu pensamento filosoficamente), o que foge da vivacidade das impressões que podem mover o pensamento.

Um fato que nos chama a atenção é que muitas vezes nem mesmo os professores tiveram contato direto com o objeto da Filosofia que poderia lhes oferecer impressões fortes sobre ela: o pensamento filosófico compreendido como um filosofar. Assim, muitas vezes aquilo que se oferece ao aluno são apresentações de algumas imagens que são pautadas em certas ideias partilhadas e difundidas de determinados estruturas de pensamentos filosóficos. Ou seja, em um certo senso comum sobre a Filosofia e sobre aquilo que os filósofos disseram. Para nós, há nesse processo um empobrecimento do pensamento que se reflete num empobrecimento da experiência do filosofar por parte do professor que, consequentemente, é transmitido ao aluno. Seguindo a esteira daquilo que

Filosofia e Educação - ISSN 1984-9605 - v. 4, no 1, abril-setembro de 2012 
faz o professor, o aluno cria uma imagem distorcida do que seja filosofar. Assim,

Ao longo de todo esse processo, a capacidade de o aluno experimentar as coisas e atribuir-lhes um sentido é debilitada pela releitura do mundo que tem como modelo a leitura feita por um filósofo, muitas vezes mediada por um comentador e explicada por um professor, fechada em si mesma. A relação entre o aluno, o filósofo, o mundo e o problema passa, assim, a constituir-se por uma forma de mediação: parte-se da relação que determinado filósofo criou com o mundo, assumindo-a como modelo para, assim, relacionar-se com o problema.

Nesse contexto, toda a relação do aluno com o mundo é mediada pelo modelo criado a partir do olhar de determinado filósofo, como se a possibilidade de uma experiência do mundo se desenhasse apenas na sombra da experiência vivenciada pelo pensamento do filósofo e não na experiência de um problema que emerge do olhar singular do aluno desde o interior do mundo. Nessa relação, o aluno não mergulha diretamente na plurivocidade problemática que é o mundo, mas é sempre mediado pelo pensamento de um filósofo. Como se não bastasse essa mediação, surgem outras: (1) a explicação do comentador, (2) a explicação de um outro comentador que explica o comentador e (3) a explicação do professor (que assume também o papel de um outro comentador). Assim, o modo de olhar o mundo é delineado na repetição das pautas de leitura das significações atribuídas pelas inúmeras mediações que antecedem e direcionam o contato do aluno com o mundo. A forma como essa relação se constitui evidencia, então, a questão de uma nítida desvalorização da experiência possível de se fazer face ao conhecimento transmitido. (GELAMO, 2009, p.119-120)

A pretensa objetividade do ensino, que impõe a necessidade de transmissão de tais representações consideradas verdadeiras, ampara essa crença de que aquilo que se pode ensinar seja necessariamente uma imagem

Filosofia e Educação - ISSN 1984-9605 - v. 4, no 1, abril-setembro de 2012 
daquilo que foi assimilado como saber filosófico. Nessa relação, então, o conhecimento que o aluno pode ter está alicerçado na aquisição de representações pretensamente verdadeiras, que são concepções claras e distintas das coisas enunciadas pelo professor, e encontram a sua verdade naquilo que o professor disse. Conhecer seria estabelecer uma representação ideal objetiva daquilo que é representado, e neste sentido, qualquer pensamento que fuja desta ideal é considerado um erro. É para evitar o erro que os professores transmitem a representação verdadeira dos objetos, ou seja, as "verdadeiras" interpretações dos filósofos e de suas ideias.

Os problemas que apresentamos a respeito dessa relação podem ser formulados da seguinte maneira: será que há realmente a necessidade de uma transmissão representacional de conhecimentos tal qual se pretende nesta concepção de ensino para que o aluno aprenda a Filosofia? Por outro lado, questionamo-nos: será que existe realmente a possibilidade da transmissão objetiva de conhecimentos e saberes capazes de fornecer, àqueles que são receptores desse processo, condições de aprender e apreender algo sobre o mundo? Será que o conhecimento pode ser transmitido de forma representacional por meio de uma explicação, sem que aquele que aprende faça uma experiência por si só daquilo que aprende?

\section{Um ensaio para se pensar um ensino não-representacional}

Essas problematizações que enunciamos acima moveram nosso pensamento durante os dois anos em que desenvolvemos o projeto PIBID nas escolas. Mais uma vez encontram respaldo no pensamento de Rancière (2002) na tentativa de pensar e encaminhar uma solução para eles. Na obra $O$ mestre ignorante o autor narra a história de Joseph Jacotot, um intelectual belga que, sem saber nenhuma palavra em holandês, se encontra na função de ensinar francês a alunos holandeses que, por sua vez, nada sabiam de francês. Com esta dificuldade comunicativa, propõe a seus alunos, por meio

Filosofia e Educação - ISSN 1984-9605 - v. 4, no 1, abril-setembro de 2012 
de um intérprete, que leiam uma edição bilíngue francês-holandês do Telêmaco publicada na época. Através do estudo do livro e realizando associações entre as duas versões, os estudantes deveriam produzir um texto em francês sobre o que haviam lido. Ao se surpreender com os excelentes resultados, Jacotot passa a se questionar sobre a função do mestre e a necessidade de explicações no processo de aprendizagem.

A história de Jacotot nos leva a desconfiar do ensino representacional e sua função explicadora. A explicação justamente por envolver relações abstratas e impossibilitar a experiência com o objeto, não determina a aprendizagem, pois esta poderia se dar em outro âmbito. Para nos ajudar a discutir essa outra possibilidade de pensar as relações que ocorrem em sala de aula, procuramos amparo na obra do filósofo francês Gilles Deleuze.

Deleuze em seu livro Diferença e Repetição (2006) promove uma crítica justamente a este sistema representacional que, segundo ele, leva à estagnação do indivíduo frente ao mundo e, no caso da Filosofia, frente aos problemas filosóficos que a nossa relação com o mundo e com o pensamento pode nos oferecer. $\mathrm{O}$ autor defende que $\mathrm{o}$ aspecto representacional forma a "imagem dogmática do pensamento" que esmaga o pensamento "sob uma imagem que é a do Mesmo e do Semelhante na representação, mas que trai profundamente o que significa pensar" (2006, p. 161). Para o autor, o pensamento não pode ser compreendido como sendo uma relação passiva face ao conhecimento, mas, ao contrário, este é impulsionado pelos signos que o afetam a buscar decifrações desses mesmos signos.

É nessa dimensão da relação com os signos que Deleuze situa a aprendizagem. Segundo Deleuze (1987), os signos agem de forma violenta sobre nós, obrigando o pensamento a buscar o seu sentido. Todo signo alguns mais que outros devido à relação afetiva de cada sujeito - apresenta

Filosofia e Educação - ISSN 1984-9605 - v. 4, no 1, abril-setembro de 2012 
uma "lacuna" que nos convida a pensar. E dessa forma, para o autor, a aprendizagem "diz respeito essencialmente aos signos" (1987, p. 4):

Os signos são objeto de um aprendizado temporal, não de um saber abstrato. Aprender é, de início, considerar uma matéria, um objeto, um ser, como se emitissem signos a serem decifrados, interpretados. Não existe aprendiz que não seja "egiptólogo" de alguma coisa. Alguém só se torna marceneiro tornando-se sensível aos signos da madeira, e médico tornando-se sensível aos signos da doença. A vocação é sempre uma predestinação com relação a signos. Tudo que nos ensina alguma coisa emite signos, todo ato de aprender é uma interpretação de signos ou de hieróglifos. $(1987$, p. 4)

Deleuze leva-nos a pensar que a aprendizagem está muito mais relacionada à necessidade de aprender do que como uma consequência do ensinar, o ensinar uma representação adequada sobre algo. A aprendizagem se dá quando algo nos toma por completo e impulsiona a busca por investir nosso pensamento na decifração daquilo que nos acomete. Nesse sentido, "o aprendizado é a produção de um encontro absolutamente novo, e do qual não podemos vislumbrar de antemão os resultados", é um encontro singular com os signos (GALLO, 2008, p. 74). Tal ideia abre uma outra possibilidade de entendermos as relações do ensino da Filosofia que não sejam reféns da transmissão representacional de conhecimentos, pois nesse viés não é possível ensinar algo a alguém, transmitir um conhecimento pronto acerca de algo ou de comunicar um saber. Nessa relação, o papel do professor seria o de "ensignar", isto é, indicar, mostrar, de modo a evidenciar os signos problemáticos do mundo por meio da Filosofia e dar o que pensar ao aluno. Como afirma Deleuze,

[...] é precisamente o signo que é objeto de um encontro e é ele que exerce sobre nós a violência. $\mathrm{O}$ acaso do encontro é que garante a necessidade

Filosofia e Educação - ISSN 1984-9605 - v. 4, no 1, abril-setembro de 2012 
daquilo que é pensado. Fortuito e inevitável, como diz Proust. [...] O que quer aquele que diz "eu quero a verdade"? Ele só a quer coagido e forçado. Só a quer sob o império de um encontro, em relação a determinado signo. Ele quer interpretar, decifrar, traduzir, encontrar o sentido do signo. (1987, p. 16).

É a isto que se deve a crítica à representação feita pelo autor, pois esta relaciona conceito e objeto, fixando sua compreensão e reafirmando sempre o Mesmo. E é também a isso que criticamos no ensino representacional. Desse modo, temos de pensar a apresentação da Filosofia não como uma representação, uma vez que "a aprendizagem não se faz na relação da representação com a ação (como reprodução do Mesmo), mas na relação do signo com a resposta (como encontro com o Outro)" (DELEUZE, 2006, p. 31). A aprendizagem só ocorre quando há essa incessante busca pelo sentido do signo, quando há uma relação do indivíduo com o objeto a ser apreendido. Quando o pensamento é genuinamente afetado pelo signo e não imposto como uma necessidade e sem qualquer relação significativa para o estudante.

A representação está vinculada à tradição de ensino que oferece os conceitos prontos para problemas resolvidos que não permitem ao aluno pensar esses mesmos problemas de forma diferente. Nesse sentido, o pensamento estaria resumido a um tipo de recognição, pensar o que já foi pensado. Neste contexto, se produz o que Deleuze chama de imagem dogmática do pensamento: este modelo que reina e que

orienta a análise filosófica do que significa pensar [...] só pode constituir um ideal de ortodoxia. A Filosofia não tem mais qualquer meio de realizar seu projeto, que era o de romper com a doxa (DELEUZE, 2006, p. 196).

Filosofia e Educação - ISSN 1984-9605 - v. 4, no 1, abril-setembro de 2012 
Parafraseando Deleuze, o ensino se constituiria na ortodoxia de impor uma imagem dogmática do que seja pensar filosoficamente por meio de fazer com que o aluno reproduza o pensamento dos filósofos e dele mesmo professor, representante dos filósofos na sala de aula, não permitindo ao aluno romper com a filodoxa (amor a doxa) que impera nas relações de ensino, ao impor que os estudantes reafirmem o mesmo que foi pensado por outros.

Tais imagens de pensamento podem ser e precisam ser ensinadas. Mas este ensino é um treinamento: somos treinados a pensar de determinada maneira. $\mathrm{Ou}$, para dizer de outra forma: não aprendemos uma imagem do pensamento não a experimentamos como novidade absoluta de nosso próprio pensamento, mas somos treinados para pensar segundo ela, investindo na recognição e na repetição do mesmo. (GALLO, 2008, p. 72)

Desse modo, só há pensamento de fato quando somos tomados por problemas que não podem ser resolvidos no domínio da imagem dogmática do pensamento de tal forma que nos forçam a pensar, violentando nosso pensamento.

Tal prática de ensino de treinamento ${ }^{3}$ não se dedica a uma experimentação de pensamento. Além do que, como já foi dito, acaba por reafirmar duas coisas: a superioridade do professor face ao aluno e a incapacidade do aluno face ao conteúdo. Nesse contexto, o professor se coloca entre o conteúdo estudado e o aluno, como se este último não tivesse as condições necessárias para entendê-lo por si só; e com o objetivo de evitar o que comumente se considera um "erro" na aprendizagem.

\footnotetext{
${ }^{3}$ Gallo (2008, p. 71-72), amparado por Pierre Lévy, defende que houve uma transição de uma educação pela experiência para um ensino como treinamento, que está relacionada à passagem da tecnologia oral para a tecnologia escrita. Este primeiro momento diz respeito ao ensino grego que era essencialmente oralista, se tratava de uma educação pela experiência e estava ligada ao uso da memória, da poesia, recitação de mitos. Esta educação foi substituída por um ensino no qual o importante era o treinamento para o exame dialético das ideias.
}

Filosofia e Educação - ISSN 1984-9605 - v. 4, no 1, abril-setembro de 2012 
Deleuze critica justamente esta concepção do "erro" concebido como "desventura" e "negativo" do pensamento (2006, p. 214). O erro está ligado a uma falsa representação - uma falha no bom senso que toma o senso comum de forma bruta - caracterizada por uma falha na percepção e pelo falso reconhecimento. Esse aspecto já tinha sido desenvolvido por Descartes, nas Meditações Metafísicas, ao tratar das falsas percepções e dos erros dos sentidos. Assim, o erro não é intrínseco ao pensamento, mas, ao contrário, causado por algo que lhe é externo. Essa falha na representação, que em Descartes pode ser causada pela falsa percepção do mundo externo pelos sentidos e pelos outros inimigos do pensamento apresentados na Primeira das suas Meditações Metafísicas (1973), produz um encadeamento negativo no processo de pensamento, pois conduz a falsas resoluções. Nessa relação está implícita uma imagem representacional que reduz o erro à figura do negativo (a besteira, a maldade e a loucura seriam reduzidas a essa figura), não aceitando as várias formas de pensar como um pensar diferente. Nessa relação, qualquer pensamento que se diferencie da imagem original é considerado um pensamento errado. Assim, a possível criação e um pensamento autônomo pelo aluno é emudecida pela voz do professor, que profere a verdade sobre aquilo que o aluno deve aprender, sobre a imagem verdadeira que ele deve pensar, enfim, sobre a correta representação que tem de ter sobre aquilo que lhe foi ensinado.

Dessa forma, não haveria espaço para o diferente no pensamento, pois este é considerado um erro que deve ser corrigido por meio de explicações que visam a promover a compreensão pelo aluno daquilo que lhe foi ensinado. Tal concepção é problemática, pois se a forma do pensamento é imposta, havendo aqueles que possuem tais representações verdadeiras e que devem transmiti-las, o processo do pensar parece se tornar desnecessário já que não se pode pensar diferentemente, restando como única opção a aquisição das representações enunciadas pelo professor. Por

Filosofia e Educação - ISSN 1984-9605 - v. 4, no 1, abril-setembro de 2012 
isso, talvez a proposta de Deleuze, de defender o espaço do diferente no pensamento para que realmente se tenha o movimento do pensamento e não a estagnação, seja importante ser levada em consideração.

Talvez a ideia de que o professor seja uma mente superior e promova explicações aos alunos que possuem uma mente inferior e que, por isso, necessitam destas informações para sua formação, seja apenas uma imagem dogmática de pensamento, para usar uma terminologia deleuziana ${ }^{4}$, de uma ação pedagógica. É esta dimensão filosófica do ensino-aprendizagem que traz Jacques Rancière em seu livro. $\mathrm{O}$ autor alerta-nos para $\mathrm{o}$ mito explicador e as relações hierárquicas que se instauram neste âmbito ao afirmar que

[...] explicar alguma coisa a alguém é, antes de mais nada, demonstrar-lhe que não pode compreendê-la por si só" (2002, p. 20). Para ele, "um professor não é, nem mais, nem menos inteligente do que qualquer outro homem; ele geralmente fornece uma grande quantidade de fatos à observação daqueles que procuram (2002, p. 108),

e nesse sentido, "o que embrutece o povo não é a falta de instrução, mas a crença na inferioridade de sua inteligência" (2002, p. 50). Desse modo, o autor nos faz refletir sobre algo que temos como tácito que é a função explicadora do professor, que é perdida se considerarmos as relações de sentido do indivíduo com o signo que de fato promove a aprendizagem. Nesta perspectiva, a diferença que há entre professor e aluno está ligada somente à relação que estes estabelecem com o objeto, e isto em nada está relacionado com superioridade ou inferioridade. A inteligência é a mesma para todos, são suas manifestações que se diferenciam.

Diante disso, colocamo-nos uma questão que violenta nosso pensamento e que nos dá a pensar: quais as condições de fazer com que a ${ }^{4}$ Cf. Deleuze, 1968.

Filosofia e Educação - ISSN 1984-9605 - v. 4, no 1, abril-setembro de 2012 
Filosofia, no âmbito escolar, violente o pensamento dos professores e dos alunos e promova o desejo/necessidade de pensar? $O$ que oferecer ao estudante para permitir que este realize a sua experiência com o pensar filosófico de tal forma a não se restringir às representações do professor sobre determinados assuntos?

\section{Considerações finais}

Todas essas questões que levantamos encontram seus obstáculos. Não podemos esquecer de que, no âmbito escolar, há uma exigência de que o conteúdo seja apresentado e "digerido" ao estudante e que o currículo seja cumprido. Há uma exigência apresentar longas explicações sobre os conceitos e temas. Essa exigência é feita não apenas por parte da instituição escolar, mas também pelos alunos, que já estão acostumados com a ordem explicadora que exige do professor as respostas e o conhecimento preciso sobre os conteúdos, de forma a apresentar respostas prontas e não um pensamento que mova o pensamento do outro.

Os alunos, em decorrência das relações de poder vigentes, são frequentemente atingidos pela súbita sensação de que, sem explicação, nada podem aprender. O professores, por outro lado, de que não podem ensinar sem encher o período todo da aula de explicações. Nessa relação emerge um sentimento de inferioridade que, por mais que o professor crie condições para que o pensamento filosófico se desenvolva, o aluno não se sente capacitado para realizar tal experiência e acredita que as representações feitas e transmitidas pelo professor é que são as verdadeiras.

A “educação filosófica", ancorada nessa noção comum do ensino representacional tem se restringido a conhecimentos acerca da história da Filosofia ou de filósofos renomados, o que muitas vezes não promove o impulso do pensar. ${ }^{5}$ Independentemente da definição que tenhamos de

\footnotetext{
${ }^{5}$ Vale ressaltar aqui que não acreditamos que o ensino da História da Filosofia não seja importante. Ao contrário, para nós, a História da Filosofia deve se constituir como fonte
}

Filosofia e Educação - ISSN 1984-9605 - v. 4, no 1, abril-setembro de 2012 
Filosofia, das várias definições que poderíamos adotar, parece-nos que algo que permanece é a preocupação com o processo do pensamento na resolução de problemas filosóficos. Porém, encontramos em seu ensino algo contrário a isso: a apresentação de algumas imagens de pensar que devem ser usadas pelos aprendizes para enquadrar a realidade.

Gallo traz à tona a necessidade de um ensino focado na aprendizagem em que "o foco esteja no processo singular de pensamento de cada um. E para isto não há método” (2008, p. 73). Nesse sentido, o ensino se constitui de um convite para o pensar. "Cada estudante precisa fazer ele próprio o movimento, ele próprio precisa experimentar o pensamento, entrar no campo problemático e experimentar o pensar por conceitos." (2008, p. 75).

Sócrates já dizia que o espanto (thaumazein) sofrido diante do mundo é que deu origem à Filosofia, pois se trata de uma busca incessante pela verdade que só pode emergir diante daquilo que nos surpreende, tomando nosso pensamento na busca de seu sentido. Uma Filosofia tal qual os seus primórdios que afirma o "só sei que nada sei" e a necessidade de uma busca interna e incessante pela verdade parece ter perdido espaço para uma tradição que indica o que e como se deve pensar visando a respostas corretas e verdadeiras numa espécie de dogmatização do pensamento. Tal sistema que determina "representações verdadeiras" contraria o que se entende por pensamento, resultando na estagnação do indivíduo. Nesse sentido, perguntamo-nos: qual o lugar para o thauma, a capacidade de ser afetado, de nos espantar, de sermos tomados pelos signos e permitir que nosso pensamento se dobre para pensar aquilo que nos afetou no ensino da filosofia?

fundamental para o desenvolvimento do ensino da Filosofia. Porém, queremos problematizar que apenas o acesso a ela não garante o sucesso no ensino da Filosofia que pretenda desenvolver uma capacidade de filosofar nos alunos. Tal ensino vai além da dimensão histórica da Filosofia, ainda que esta última também tenha sua importância.

Filosofia e Educação - ISSN 1984-9605 - v. 4, no 1, abril-setembro de 2012 
Diante disso, parece-nos mister pensar as relações no ensino da Filosofia vinculado à especificidade da aprendizagem filosófica, que tenha o objetivo de promover o pensamento e não que se ocupe apenas de transmitir representações adequadas sobre algo. Este, acreditamos se dar também por meio da dimensão estética, ou, para sermos mais precisos, naquilo que Aristóteles chamou de Thaumazein, pois é da ordem dos afetos e não da ordem puramente epistemológica que o pensamento é movido, já que exige que aquele que pensa seja arrebatado pelo problema e invista-se em decifrálo.

\section{Referências bibliográficas}

DELEUZE, G. Diferença e repetição. Tradução de Luiz Orlandi, Roberto Machado. Rio de Janeiro: Graal, 2006.

Proust e os signos. Tradução de Antonio Piquet e Roberto Machado. Rio de Janeiro: Forense Universitária, 1987.

; GUATTARI, F. O que é filosofia? Rio de Janeiro: Editora 34, 1992.

DESCARTES, R. Discurso do método; Meditações; Objeções e respostas; As paixões da alma; Cartas. Tradução de J. Guinsburg e Bento Prado Júnior São Paulo: Abril Cultural, 1973. (Coleção Os pensadores).

GALLO, S. Filosofia e o exercício do pensamento conceitual na educação básica. Educação e Filosofia , v. 22, p. 55-78, 2008.

GELAMO, R. P. O ensino da filosofia no limiar da contemporaneidade : o que faz o filósofo quando seu ofício é ser professor de filosofia? São Paulo: Cultura Acadêmica, 2009.

HUME, D. Investigação sobre o entendimento bumano. São Paulo: Editora UNESP, 1999.

RANCIÈRE, J. O Mestre Ignorante: cinco lições sobre a emancipação intelectual (trad. Lilian do Valle). Belo Horizonte: Autêntica, 2002.

Filosofia e Educação - ISSN 1984-9605 - v. 4, no 1, abril-setembro de 2012 